\title{
SIGNIFICANCE OF MAST CELLS IN BENIGN AND IMALIGNANT CONDITIONS OF PROSTATE
}

KEY WORDS: Mast cell Prostate, Benign, Malignant

\section{Hemanth Kumar}

\section{Dr R M Potekar}

\section{Dr Satish Arakeri*}

Final year MBBS student, BLDE ( Deemed to be University), Shri B M Patil medical college and research hospital,Vijayapur, Karnataka, India.

Professor, Dept of Pathology, BLDE ( Deemed to be University), Shri B M Patil medical college and research hospital,Vijayapur, Karnataka, India.

Associate professor, Dept of Pathology, BLDE ( Deemed to be University), Shri B M Patil medical college and research hospital, Vijayapur, Karnataka, India. *Corresponding Author

Introduction: Mast cells are the one of the component of defense immunity of our body. Aims of the study: Role of mast cell in benign and malignant condition of prostate. Materials \& methods: Total number of cases is 32 . Out of 32 cases, 24 cases are Benign (BPH) and 8 cases are malignant. Special stain ie. Toluidine blue has been done in all the 32 cases, as toluidine blue stain will highlight the mast cells accurately. The number of mast cells per 10 high power fields in both benign and malignant conditions was compared using statistical tools. Results: Proportion of mast cell in benign lesions is 0.58 while in malignancy is 0.63 . Since the $p$-value was $>0.05$, the results were considered as statistically insignificant. Discussion: In the present study, it is found that there is no statistical significant increase in the number of mast cells. Conclusion: Hence probably mast cells may not play any protumorogenic role in cases of prostatic malignancy.

\section{INTRODUCTION:}

Mast cells are the one of the component of defense immunity of our body. It particularly acts as bactericidal ${ }^{1,2}$. Its activation causes initiation of allergic reactions, in some conditions leads to anaphylactic reactions. It functions in recruiting the other immune cells at the site of need ${ }^{3,4}$. Mast cells also become a part of mixed inflammatory cells associated with malignancy. They form the part of desmoplastic reaction surrounding the tumor which is in the stage of infiltration. Mast cells secrete both tumorigenic factors like angiogenic factors and anti tumor factors like TNF $\alpha$ and IL 9 . In tumors arising in stomach , thyroid, it is supposedly act like pro tumorigenic, whereas in case of breast cancers, it probably have protective role. But in variety of other malignancies, it is merely a standby player of unknown significance ${ }^{5}$. Hence, in the present study, a sincere attempt has been made to compare the significant presence of mast cells in prostatic malignancy.

\section{MATERIALS AND METHODS:}

In the present study, both carcinoma prostate and benign prostatic hyperplasia(BPH) cases have been taken. Total number of cases is 32 . Out of 32 cases, 24 cases are Benign (BPH) and 8 cases are malignant. BPH will act as control samples. H\&E stained slides of both benign and malignant cases were reviewed for confirmation of the diagnosis. Special stain ie. Toluidine blue has been done in all the 32 cases, as toluidine blue stain will highlight the mast cells accurately. Then count of the mast cells has been done in $40 \mathrm{x}$ (High power) in a total of 20 fields in each slide. Average number of mast cells was calculated per 10 high power field. The number of mast cells per 10 high power fields in both benign and malignant conditions was compared using statistical tools.

Duration of study was 6 months

\section{Inclusion criteria:}

1. All malignant cases were reviewed by two pathologists.

2. BPH cases were taken as a control samples.

\section{Exclusion cases:}

1. Suspicious/atypical/Intraepithelial lesion were excluded

\section{RESULTS:}

All 32 cases are reviewed and classified into benign (24 cases) and malignant ( 8 cases). Toluidine blue staining has been done in all cases and mast cells counted per 10 high power field in all 32 cases. The results of the study is mentioned below:

\section{Benign lesions:}

Range of mast cells in benign lesions: 0-2 / $10 \mathrm{HPF}$

Average number of mast cells in benign lesions: 0.58

Number of benign lesions with no mast cells per $10 \mathrm{HPF}: 13$

Number of benign lesions with 01 mast cells per 10 HPF: 08

Number of benign lesions with 02 mast cells per 10 HPF:03

\section{Malignant lesions:}

Range of mast cells in malignant lesions: 0-2 / $10 \mathrm{HPF}$

Average number of mast cells in benign lesions: 0.62

Number of malignant lesions with no mast cells per $10 \mathrm{HPF}: 05$

Number of malignant lesions with 01 mast cells per $10 \mathrm{HPF}: 01$

Number of malignant lesions with 02 mast cells per 10 HPF: 02

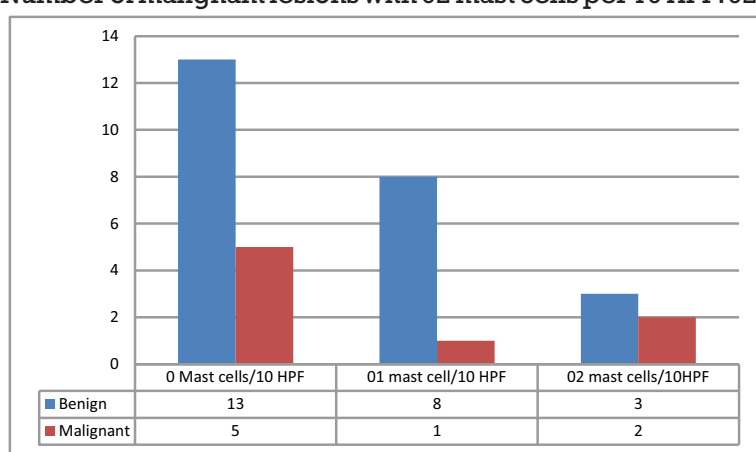

* Graph 01: Distribution of mast cells in benign and malignant lesions

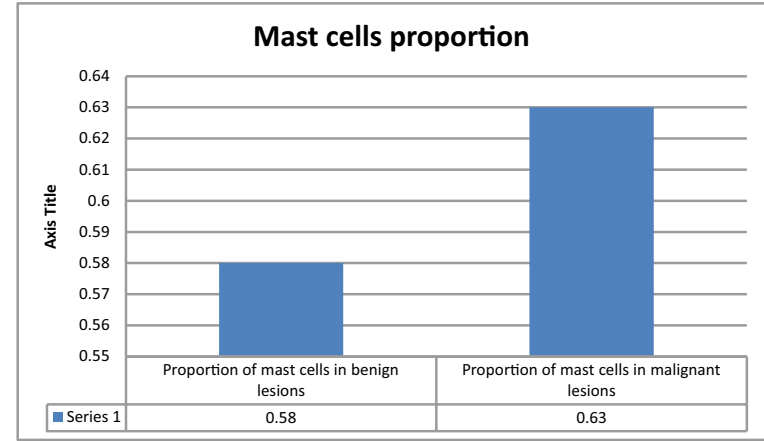

* Graph 02: Distribution of Mast cells Between Study Groups 


* Table 01: Proportional distribution of Mast cells
Between Study Groups
\begin{tabular}{|l|c|}
\hline Total number of mast cells present in benign lesions & 14 \\
\hline Sample Size of benign lesions & 24 \\
\hline Proportion of mast cell in Benign lesions & $\mathbf{0 . 5 8}$ \\
\hline Total number mast cells present in malignant lesions & 5 \\
\hline Sample Size of malignant lesions & 8 \\
\hline Proportion of mast cell in malignant lesions & $\mathbf{0 . 6 3}$ \\
\hline Chi square p-value & $\mathbf{0 . 8 3 5}$ \\
\hline
\end{tabular}

\section{Statistical analysis}

All characteristics were summarized descriptively. Chisquare $\left(\chi^{2}\right)$ test was used for association between two categorical variables. Since the p-value was $>0.05$, the results were considered as statistically insignificant. Data were analyzed using SPSS software v.23.0 and Microsoft office 2007

\section{DISCUSSION:}

In the present study, total 32 cases of both benign and malignant lesions are included. Quantitative estimation of mast cells is done. It is found that there is no statistical significant increase in the number of mast cells. Hence probably mast cells may not play any protumorogenic role in cases of prostatic malignancy.

According to the study conducted by Heidi $A^{6}$, It was observed that intratumoral mast cells may be protective against prostate cancer. The study conducted by pittoni et $\mathrm{al}^{7}$ shows the data underscore the contribution of mast cells in tumor progression and shows the role of mast cells in protecting against the occurrence of aggressive $\mathrm{NE}$ variants in prostate cancer.

In the study conducted by Vani et al ${ }^{8}$, Mast cell count was higher in benign lesion when compared to malignancy. Mast cells were located predominantly in stromal region in both BPH and adenocarcinoma prostate. The author concluded that significant increase in mast cell count in stroma is observed in BPH compared to adenocarcinoma of prostate, indicating that mast cell density is inversely proportional to malignancy.

In the study conducted by Johannason $A{ }^{9}$, It was observed mast cells may not have protumorogenic role, but it presence may act as prognostic marker as it may helpful in stimulating angiogenesis. It also plays role in tumor progression by causing angiogenesis. Its number is also increased in the stroma as a part of desmoplastic reaction. In the study conducted by Rakshit $\mathrm{v}^{10}$, It was seen that there is significant increase in number of mast cells in carcinoma prostate compared to benign prostatic hyperplasia. It is also observed that mast cells count is increased as the grade of the tumor increases, but found no correlation with PSA levels.

In the study conducted by Tavarn et al ${ }^{11}$, It was observed that increased in mast cells aids in tumor infiltration. But its number will not increase in malignant lesions when compared to benign prostatic lesions. According to MA Z et al ${ }^{12}$, Mast cells help in proliferation of prostate cancer cells and the occurrence of epithelial mesenchymal transition (EMT), which will lead to invasion and metastasis of prostate cancer cells.

The study conducted by wanfu $\mathrm{Xu}^{13}$ shows that Protein kinase $\mathrm{D}(\mathrm{PKD} 2 / 3)$ stimulate the mast cells recruitment and tumor angiogenesis in the adenocarcinoma of prostate. PKD2/3 silencing in tumor cells of adenocarcinoma of prostate markedly decreased the mast cell migration. Hence tumor infiltrate and progression is increased due to mast cell infiltration.

Thus till now, all the studies mentioned above shows both pros and cons regarding the mast cells in prostate. Few are in favor of protumorigenc effect and few are anti tumorigenic. But In case of carcinoma prostate, mast cells favors tumor infiltration and progression as it is observed in most studies.

In our study, proportion of mast cells in benign and malignant lesions are compared and found no statistical significant increase in the number of mast cells in malignancy. This study will continue further to include more number of malignant cases as their number is very less compared to benign lesions and to see the effects of mast cells in prostatic cancer.

\section{CONCLUSION:}

The role of mast cells as pro and anti tumorogenic action is controversial as both possibilities are seen in various literatures. In our study, it is concluded that the mast cell probably don't have any protumorigenic role.

\section{Acknowledgement:Nil}

\section{REFERENCES:}

1. DeBruin EJ, Gold M, Lo BC, Snyder K, Cait A, Lasic N et al. Mast cells in human health and disease. Methods Mol Biol. 2015;1220:93-1 19.

2. Silva EZM, Jamur MC,Oliver C. Mast Cell Function-A New Vision of an Old Cell.J Histochem Cytochem. 2014 Oct; 62(10):698-738.

3. Whittemore MK,Dileepan KN,Wood JG. Mast Cell: A Multi-Functional Master Cell. Front Immunol.2015;6:620.

4. Bischoff SC. Role of mast cells in allergic and non-allergic immune responses: comparison of human and murine data.Nat Rev Immunol 7, 93-104 (2007).

5. GildaV, Maria RG, Stefania L, Giancarlo M, Raffaella L, Gianni M et al. Are Mast Cells MASTers in Cancer?. Front Immunol. 2017;8:424.

6. Hempel H, Cuka NS, Kulac , Barber JR, Cornish TC, Platz EA et al. Low Intratumoral Mast Cells Are Associated With a Higher Risk of Prostate Cancer Recurrence..Prostate.2016.

7. Pittoni P, Tripodo C, Piconese S, Mauri G, Parenza M, Rigoni A et al. Mast Cell Targeting Hampers Prostate Adenocarcinoma Development but Promotes the Occurrence of Highly Malignant Neuroendocrine Cancers. Cancer Res. 2011 Sep 15;71(18):5987-97.

8. Vani D, Kumari BSA, Bharathi M. Consortum between mast cell and prostatic lesions-An etiological factor or mere coexistence. Indian Journal of Pathology and Oncology 2020;7(1):171-175.

9. Johansson A, Rudolfsson S,Hammarsten P,Halin S,Pietras K,Jones J et al. Mast Cells Are Novel Independent Prognostic Markers in Prostate Cancer and Represent a Target for Therapy. Am J Pathol.2010 Aug; 177 (2): 1031-1041.

10. Rakshith V, Kumar ML. Study of mast cells in prostate lesions: Adenocarcinoma compared with hyperplasia. Clin Cancer Investig J 2016;5:12 1-5.

11. Taverna G, Giusti G, Seveso M, Hurle R, Colombo P, Stifter S et al. Mast Cells as a Potential Prognostic Marker in Prostate Cancer. Dis Markers. 2013; 35(6): 711-720.

12. Ma Z, Yue L, Xu Z, Zeng S, Ma Y, Li Z,Wei Li et al. The effect of mast cells on the biological characteristics of prostate cancer cells. Cent Eur J Immunol. 2018; $43(1): 1-8$.

13. Wanfu Zu, Jiabi Q, Fangyin Z, Songyu Li, Wenjing G, Liping C et al Protein kinase Ds promote tumor angiogenesis through mast cell recruitment and expression of angiogenic factors in prostate cancer microenvironment.J Exp Clin Cancer Res 38, 114 (2019). 